\title{
MOTIVAÇÃO NO ESPORTE INFANTO JUVENIL
}

Marcelo Callegari Zanetti

Tiago Nicola Lavoura

Afonso Antonio Machado

\section{Resumo}

Esta pesquisa quali-quantitativa, de formato descritivo, teve como objetivo investigar por meio de um questionário estruturado, composto por uma única questão, os motivos apresentados por 30 atletas, com idade entre 12 e 19 anos (14.5 \pm 1.5 ), para a procura da modalidade voleibol. Como resultado, encontramos os seguintes motivos: prazer (28.9\%), influência da família (13.3\%), ser um(a) grande atleta (11.1\%), aprender a trabalhar em equipe (8.9\%), fazer uma atividade física/esporte (6.7\%), influência dos amigos (6.7\%) e outros motivos (24.4\%). O conhecimento dos motivos apresentados para a prática da modalidade investigada poderá auxiliar aos técnicos e dirigentes esportivos na adoção de condutas que promovam maior adesão destes indivíduos no contexto esportivo, e, conseqüentemente, a busca pela excelência na modalidade no futuro.

\section{Palavras-Chave}

Motivação; Esporte; Desempenho.

\section{MOTIVATION IN THE SPORT INFANT JUVENILE}

Marcelo Callegari Zanetti

Tiago Nicola Lavoura

Afonso Antonio Machado

\begin{abstract}
This quali-quantitative research, of descriptive format, had as objective to investigate by means of a structuralized questionnaire, composed for an only question, the reasons presented for 30 athletes, with age between 12 and 19 years $(14.5 \pm 1.5)$, for the search of the modality volleyball. As result, we find the following reasons: pleasure $(28.9 \%)$, influence of the family $(13.3 \%)$, to be a great athlete $(11.1 \%)$, to learn how to work as a team $(8.9 \%)$, to make a physical activity and sport $(6.7 \%)$, friend's influence $(6.7 \%)$ and other reasons $(24.4 \%)$. The knowledge of the reasons presented for the practical one of the investigated modality will be able to assist the coaches and directors in the adoption of behaviors that promote higher adhesion of these individuals in the sportive context, and, consequently, the search for the excellence in the modality in the future.
\end{abstract}

\section{Key-Words:}

Motivation; Sport; Performance. 


\section{INTRODUÇÃO}

Estudar a motivação no esporte nos remete a buscar entender alguns porquês relacionados com a prática esportiva, no qual, seleção e preferência, intensidade e vigor, persistência e continuidade estarão sempre atrelados ao que poderíamos chamar de dimensões motivacionais (direção, intensidade e persistência).

Neste sentido, para Weinberg e Gould (2001), a motivação é um conceito que deve ser utilizado para compreender o complexo processo que coordena e dirige a direção e a intensidade de esforço dos seres humanos, o que torna, fundamental que técnicos e dirigentes esportivos reconheçam os fatores intervenientes no processo motivacional de seus atletas. Já que, entender o que leva um indivíduo a praticar determinada atividade esportiva e, ainda, compreender o que faz com que um sujeito esteja mais motivado do que outro corresponde a conhecimentos que devem fazer parte das bases e diretrizes do processo de treinamento, seja ele, de iniciação ou de alto rendimento.

Comumente a motivação também recebe duas classificações básicas: motivos intrínsecos e motivos extrínsecos. Conforme Cruz (1996), nas recompensas extrínsecas, a motivação do indivíduo está relacionada a fatores externos, providos de outras pessoas e do ambiente, sob a forma de reforços positivos ou negativos. Entretanto, a motivação pode estar relacionada com fatores internos, que afloram do próprio interior do sujeito, ou seja, por razões intrínsecas. Porém, apenas o conhecimento desta classificação básica não nos fornece subsídios suficientes para uma discussão mais aprofundada sobre o assunto, tornando assim, necessária uma análise das teorias relacionadas à motivação.

Talvez, uma das primeiras teorias formuladas seja a teoria da realização das necessidades, pioneiramente analisada por McClelland (1961) e Atkinson (1974), que leva em conta, além dos fatores individuais e pessoais, os fatores situacionais. Neste sentido, ela busca compreender a motivação direcionada para o sucesso e a motivação direcionada para evitar o fracasso, mas também, considera a probabilidade de sucesso e os valores de incentivo para tal. Para Weinberg e Gould (2001) nesta teoria, as relações entre motivos para a realização com êxito e os motivos para se evitar o fracasso desencadearia reações emocionais (podendo ser classificadas como positivas ou negativas) e comportamentos de realização (de êxito ou de fracasso).

Outra teoria de motivação no esporte corresponde à importância das percepções de competência pessoal. Segundo este modelo, primeiramente formulado por Harter (1978), a percepção que os indivíduos possuem de suas próprias competências é fundamental para que estes possam se sentir 
motivados, para a prática esportiva. Portanto, tais percepções, ou seja, a conscientização das próprias capacidades, estabelecidas com os resultados positivos das ações, passa a ser fonte fundamental de motivação.

Um terceiro modelo teórico de motivação corresponde à teoria dos objetivos de realização, evidenciada por Nicholls (1984), Dweck (1986) e Ames (1992), no qual, faz alusão à importância dos objetivos no âmbito do esporte, e confere a eles potencial fonte de motivação, já que os mesmos norteariam as ações dos sujeitos em busca de suas realizações.

Já, o modelo do compromisso ou comprometimento com o esporte, elaborado por Scanlan et al. (1993), sustenta a importância de se saber os fatores ou motivos que explicam o compromisso ou o comprometimento do indivíduo com a prática esportiva, sendo este representado por um desejo. Esta teoria é norteada por cinco categorias essenciais, a saber: o prazer no esporte; alternativas de desenvolvimento; oportunidades de envolvimento; investimentos pessoais e pressões sociais.

Outro modelo teórico importante relacionado com a motivação é a teoria das atribuições causais, que se expressa pelos julgamentos, causas e maneiras como os atletas percebem e explicam seus resultados esportivos, sejam de êxito ou de fracasso. Tais atribuições podem ser evidenciadas por um eixo de causalidade (uma causa interna ou externa), outro de estabilidade (causa estável ou instável) e um último eixo de controlabilidade (causa controlável ou incontrolável). Sendo assim, a teoria das atribuições causais acaba por investigar as causas atribuídas às ações com êxito ou fracasso, como, por exemplo, um atleta que atribui sua derrota por nunca treinar esforçadamente. Aqui, provavelmente ele atribuiria tal fato por uma causa interna (ele não treina), estável (por manter uma constância no tempo) e controlável (é passível de ser controlada), todas essas dimensões influenciariam na motivação do sujeito (FONSECA, 1996).

Por último, porém, não menos importante temos a teoria da auto-eficácia, primordialmente apresentada por Bandura (1990; 1993; 1995), que corresponde às crenças e julgamentos pessoais, que o sujeito possui dele mesmo, de que se ele é capaz de realizar com êxito ações específicas. Para Mcauley e Mihalko (1998) esse julgamento pode ser alimentado por diversas fontes, como: experiências de sucesso; fontes vicárias (modelagem, observação); persuasão verbal; experiências emocionais e de imaginação e alguns estados fisiológicos, que estarão relacionados diretamente ao processo motivacional. 
Após discutirmos as principais teorias motivacionais, é necessário também que estejamos atentos às interferências externas presentes no processo motivacional. Neste sentido, Murcia, Gimeno e Coll (2007), consideram o técnico um dos grandes responsáveis na condução deste processo, já que o mesmo pode auxiliar os atletas na orientação de suas metas, fazendo com que estes sejam mais persistentes, despendam maiores esforços e conseqüentemente tenham maior rendimento. Machado (2006) acredita ainda que o técnico é o principal responsável pela aprendizagem da criança, tendo por função orientá-las e corrigi-las, dar motivos para que as crianças possam desempenhar o seu papel da melhor maneira possível e como agente facilitador, ajudar a criança nas relações interpessoais com os outros companheiros do grupo.

Weinberg e Gould (2001) creditam aos pais e a família das crianças grande responsabilidade no direcionamento dos mesmos à atividade esportiva, no qual, as orientações aos objetivos das crianças são significativamente relacionadas àqueles adotados por seus pais, ou seja, muitas vezes, o pai tenta fazer do filho aquilo que ele sempre sonhou, mas, nunca conseguiu. Estes autores consideram que os pais podem desempenhar um papel altamente positivo e/ou altamente negativo na experiência esportiva das crianças. Porém, um grande desafio para as pessoas envolvidas com esportes juvenis (principalmente técnicos e dirigentes) é identificar as formas precisas com que os pais podem afetar positivamente a experiência das crianças e encorajá-los a empregarem essas práticas, e, por outro lado, identificar ações negativas e facilitar os esforços para eliminá-las. Após a investigação teórica sobre a motivação, passaremos à discussão da formatação empregada no desenvolvimento do trabalho.

\section{OBJETIVOS}

O objetivo desta pesquisa foi investigar quais fatores mais motivaram indivíduos de ambos os sexos, a optarem pela prática da modalidade voleibol, enfatizando assim, a dimensão "direção". Para que chegássemos a tal objetivo, adotamos um questionário direcionado, de uma única pergunta, em que os 30 atletas investigados expressaram suas metas, na adoção do esporte.

\section{METODOLOGIA}

Esta pesquisa quali-quantitativa, de formato descritivo (THOMAS; NELSON, 2002) foi realizada de acordo com a análise quali-quantitativa, cujos dados foram tabulados, e apresentados em valores percentuais, seguidos de uma leitura descritiva dos mesmos. A opção por este procedimento metodológico se deve ao fato de que a análise descritiva nos permitiu analisar as características específicas do contexto avaliado. 
Como instrumento de coleta das informações, foi adotado um questionário estruturado, com uma única questão aberta, já que, segundo Gil (1994), as perguntas que compõem um questionário devem ser formuladas para descobrir o porquê de algo ou alguma coisa. Neste sentido, uma única pergunta nos pareceu suficiente para investigar os fatores que mais motivaram os(as) atletas a procurar a modalidade esportiva pesquisada. Estes indivíduos também foram orientados a apresentar como respostas até três motivos.

Participaram da pesquisa, 30 atletas (18 mulheres e 12 homens), da cidade de São José do Rio Pardo SP, com idade entre 12 e 19 anos $(14.5 \pm 1.5)$ e que participavam regularmente de campeonatos regionais de voleibol em suas devidas categorias, promovidos pela Associação Pró Voleibol, com sede na cidade de Porto Ferreira - SP. Os dados foram coletados no mês de julho de 2007, de acordo com as exigências de Comitês de Ética em Pesquisa, envolvendo seres humanos (Resol. 196/96 do CNS).

\section{RESULTADOS}

Como resultado, os(as) atletas apresentaram os seguintes motivos para a procura da modalidade investigada: prazer (28.9\%), influência da família (13.3\%), ser um(a) grande atleta (11.1\%), aprender a trabalhar em equipe (8.9\%), fazer uma atividade física/esporte (6.7\%), influência dos amigos $(6.7 \%)$ e outros motivos (competir, influência da televisão, porque o esporte faz bem, aprender a modalidade, identificação com o esporte, o clube ter boas equipes, receber elogios e ser saudável) (24.4\%) (Figura 1).

Ao analisarmos os resultados, pudemos verificar que apesar dos(as) atletas participarem regularmente de competições, a prática da modalidade parece ter sido mais influenciada pelo prazer e pela família, distanciando-se um pouco da busca pela competição, o que, parece estar de acordo com Weinberg e Gould (2001) e Juan, Montes e Suárez (2007), que também constataram que geralmente as crianças procuram uma modalidade esportiva principalmente para se divertir, e que as razões relacionadas com a prática competitiva da atividade físico-desportiva (gosto de competir, fazer uma carreira desportiva, vencer) não são razões freqüentemente citadas para a prática esportiva.

Juan, Montes e Suárez (2007) consideram ainda que os jovens atletas geralmente têm múltiplas razões para praticar esportes, que também podem ser determinadas pelo contexto da população que a realiza, análise esta, compartilhada por Machado (2006), que acredita que a escolha da atividade esportiva pela criança poderá ser também influenciada pela situação econômica dos pais, sendo esta situação diretamente ligada a classe social, cultura e relações profissionais apresentadas pela família. 
Este autor aponta ainda que as disponibilidades econômicas influem também na opção esportiva, pois, quanto menores estas disponibilidades, maiores serão as chances de os filhos praticarem esportes que exigem um baixo investimento, ou, então, deixarem a prática para envolverem-se em atividades mais lucrativas.

Em seu trabalho, Juan, Montes e Suárez (2007) encontraram como principais motivos para a participação esportiva de crianças: manter ou melhorar a saúde, porque gosta de exercício e esporte, estética, relacionar-se socialmente e relaxar. Pinto et al. (2007) constataram entre os motivos mais citados para a prática do voleibol: excitação e desafios, afiliação, desenvolver habilidades, reconhecimento e status, aptidão e liberar tensões. Estes autores consideram ainda, que na maioria das vezes a criança é influenciada pelos pais para iniciarem em uma modalidade esportiva, o que também pode ser evidenciado em nosso estudo. Já, Weinberg e Gould (2001), encontraram como principais motivos para a participação esportiva de crianças: divertir-se, aprender novas habilidades, fazer alguma coisa na qual são boas, estar com amigos, fazer novas amizades, condicionamento, exercícios e experimentar sucesso, que podem ser considerados, principalmente, de natureza intrínseca.

Ao discutirmos os resultados à luz das teorias motivacionais, constatamos, que, talvez, o modelo do compromisso ou comprometimento com o esporte, elaborado por Scanlan et al. (1993), seja o que melhor se enquadre nos resultados encontrados, já que, para que haja o engajamento em determinada modalidade esportiva é necessário, acima de tudo, um desejo, que pode estar ligado ao prazer no esporte, alternativas de desenvolvimento, oportunidades de envolvimento, investimentos pessoais e pressões sociais. Todos esses fatores sejam individualmente ou coletivamente, darão o norte à escolha esportiva destas crianças, e, quase sempre, sofrerão influências internas (que estão relacionadas à motivação intrínseca) e externas (pais, amigos, professores, mídia, etc.). 
Figura 1: Motivos citados para a prática esportiva

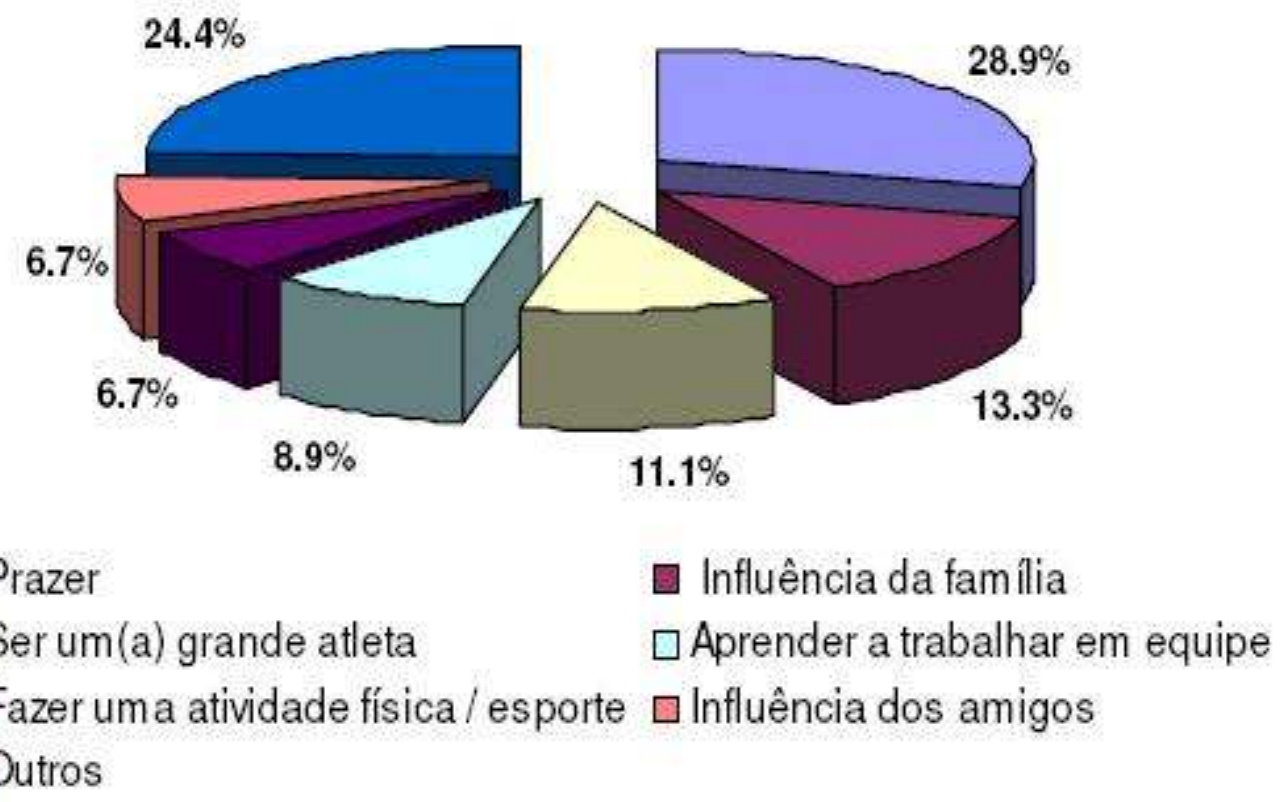

\section{CONCLUSÕES}

Os estudos relacionados à motivação ainda configuram-se como tema de grande relevância nos dias de hoje, já que, em qualquer etapa de nossas vidas a motivação estará presente, auxiliando-nos, como abordado no início de nosso trabalho, na direção, intensidade e persistência em nossas ações, podendo, impulsionar nosso crescimento nas mais diversas esferas da vida, seja ela, pessoal, profissional, social, amorosa, espiritual, etc., ou, nos colocar em estado de letargia.

No esporte, estudar a motivação também é de extrema importância, já que, a partir dos resultados encontrados, poderemos orientar melhor nossas crianças para a procura de determinadas modalidades esportivas; contribuir para aumentar a taxa de adesão dessas crianças no esporte, diminuindo assim, a fuga precoce de nossas crianças das quadras, piscinas, campos e locais de prática de atividade física e esporte; ou até, fazer com que os esforços despendidos nos treinos e jogos por esses atletas, sejam potencializados, e, conseqüentemente, os mesmos possam atingir melhores resultados.

Durante o processo de treinamento os técnicos e dirigentes desportivos também desempenham papel fundamental no processo motivacional, já que, caberá primeiramente a eles a função de orientar a iniciação destes jovens atletas; corrigir as condutas indesejadas dos pais; empregar condutas que possam contribuir para que essas crianças se mantenham motivadas durante os treinamentos e jogos, e, conseqüentemente não abandonem tal prática. 
Dentre essas condutas, Weinberg e Gould (2001) citam que os técnicos poderão aumentar a adesão e motivação dos atletas jovens fazendo com que os mesmos sintam-se competentes ao realizar as atividades propostas; ajustem as sessões de treinamento às razões pelas quais os atletas procuraram aquela modalidade, lembrando, e claro, de corrigir as ações freqüentemente, já que, os motivos podem mudar com o tempo; estimulem o relacionamento entre os pares, contribuindo assim para o aumento da adesão e o desenvolvimento psicológico e social; mudar o ambiente para aumentar a motivação, já que, os treinamentos realizados sempre no mesmo ambiente podem ser desestimulantes; mudar freqüentemente os treinamentos, para que os mesmos não sejam monótonos. Para Martin (2001), reforçadores como: faixas, medalhas, cumprimentos, elogios, aprovação e atenção dos amigos e técnico também podem ter um poderoso efeito para alguns atletas. Todas essas condutas, aliadas a um bom conhecimento do técnico em relação aos seus atletas poderão contribuir para maximizar a participação destes indivíduos, e, conseqüentemente, tornar o processo de treinamento muito mais sadio.

\section{REFERÊNCIAS}

AMES, C. Achievement goals, motivational climate, and motivational processes. In: ROBERTS, G.; C. (Ed.). Motivation in sport and exercise. Champaign: Human Kinetics, 1992. p. 161-176.

ATKINSON, J. The mainstream of achievement-oriented activity. ATKINSON, J.; RAYNOR, J. (Ed.). Motivation and achievement. New York: Halstead, 1974.

BANDURA, A. Perceived self-efficacy in cognitive development and functioning. Educational Psychologist, v. 28, p. 117-148, 1993.

B ANDURA, A. Perceived self-efficacy in the exercise of personal agency. Journal of Applied Sport Psychology, v. 2, p. 128-163, 1990.

BANDURA, A. Self-efficacy in changing societies. New York: Cambridge University Press, 1995.

CRUZ, J. F. Motivação para a prática e competição desportiva. In: CRUZ, J. F. Manual de psicologia do desporto. Braga: Lusografe, 1996.

DWECK, C. Motivational processes affecting learning. American Psychologist, v . 41, p. 1040-1048, 1986.

FONSECA, A. M. As atribuições causais em contextos desportivos. In: CRUZ, J. F. Manual de psicologia do desporto. Braga: Lusografe, 1996.

GIL, A. C. Métodos e técnicas de pesquisa social. 4. São Paulo: Atlas, 1994.

HARTER, S. Effectance motivation reconsidered: toward a developmental model. Human Development, v. 1, p. 34-64, 1978. 
JUAN, F. R.; MONTES, M. E. G.; SUÁREZ, A. D. Análisis de las motivaciones de práctica de actividad fisica y de abandono deportivo en la Ciudad de La Habana (Cuba). Anales de Psicología, Murcia, v. 23, n. 1, p. 152-166, 2007.

MACHADO, A. A. Psicologia do esporte: da educação física escolar ao esporte de alto nível. Rio de Janeiro: Guanabara Koogan, 2006.

MARTIN, G. L. Consultoria em Psicologia do Esporte: orientações práticas em análise do comportamento. Campinas: Instituto de Análise do Comportamento, 2001.

MCAULEY, E., MIHALKO, S. L. Measuring exercise-related self-efficacy. In: DUDA, J. L. Advances in Sport and Exercise Psychology: Measurement. Purdue University: Book Crafters, 1998. p. 371-390.

MCCLELLAND, D. The achieving society. New York: Free Press, 1961.

MURCIA, J. A. M.; GIMENO, E. C.; COLL, D. G. Young athletes motivational profiles. Journal of Sports Science and Medicine, v. 6, p. 172-179, 2007.

NICHOLLS, J. Achievement motivation: conceptions of ability, subjective experience, task choice, and performance. Psychological Review, v. 91, p. 328-346, 1984.

PINTO, M. V. M. et al. Estudo da relação dos sintomas de estresse pré-competitivo e dos fatores motivacionais dos atletas de voleibol. Lecturas Educación Física y Deportes, Buenos Aires, Año 12, n. 113, 2007. Disponível em: <http://www.efdeportes.com/efd113/estresse-precompetitivo-dos-atletas-de-voleibol.htm>. Acesso em: 27 out. 2007.

SCANLAN, T. K. et al. The Sport commitment model: measurement development for the youth-sport domain. Journal of Sport \& Exercise Psychology, v. 15, p. 16-38, 1993.

THOMAS, J. R.; NELSON, J. K. Métodos de pesquisa em atividade física. 3. ed. Porto Alegre: Artmed, 2002.

WEINBERG, R. S.; GOULD, D. Fundamentos da psicologia do esporte e do exercício. 2. ed. Porto Alegre: Artmed, 2001. 


\section{Marcelo Callegari Zanetti \\ UNESP - Rio Claro}

\section{Tiago Nicola Lavoura}

Universidade Vale do Rio Doce

\section{Afonso Antonio Machado \\ Instituto de Biociências de Rio Claro}

\section{Referência do artigo:}

\section{ABNT}

ZANETTI, M. C., LAVOURA, T. N., MACHADO A. A. Motivação no esporte infanto juvenil. Conexões, v. 6, p. 438-447, 2008.

\section{APA}

Zanetti, M. C., Lavoura, T. N., \& Machado, A. A. (2008) Motivação no esporte infanto juvenil. Conexões, 6, 438-447.

\section{VANCOUVER}

Zanetti MC, Lavoura TN, Machado AA. Motivação no esporte infanto juvenil. Conexões, 2008; 6: 438-447. 